\title{
Six Sigma and Developing Countries
}

\author{
Ali Rizwan, PhD \\ University of Engineering E Technology Taxila \\ Pakistan
}

\section{Introduction}

This chapter deals with issues of Six Sigma in the context of developing countries like Pakistan. Based on interviews and discussions with different segments of society, it provides an insight about their perceptions as well as their misconceptions from this latest quality concept and the challenges, which organizations face while trying to implement Six Sigma. Different public and private sector organizations are analyzed for this purpose, similarly, the role of developed countries are also discussed alongside to further enrich this study.

Six Sigma is one of the latest quality tools that utilize data and statistical analysis to measure and improve a company's operational performance, practices and systems. Six sigma is gradually becoming a popular process enhancement methodology that started in the manufacturing sector and has now spread to other areas as well. It helps in the identification and prevention of defects in manufacturing and service-related processes. This innovative and highly organized technique is introduced by Motorola. Nowadays, it is enjoying widespread recognition in many developed countries of the world. It helps in quality improvement by minimizing the cost of production, reducing the rate of defects, increasing yield, attracting customer, and so increases the profitability of business. Interestingly, it has yet not gained the status of a common technique in the developing countries. As we see that entrepreneurship and creativity are not common in the developing countries, so there are some hurdles in the promotion of this technique in these countries. Also, the trend of this technique in private sector differs from the public sector. As private sectors are more independent in their decision making and free in managing their financial resources. Whereas public sectors are more bound to the rules and regulations set forth for them. It is therefore difficult for the public sector organizational leaders to make drastic changes in the policies set forth by their respective governments. Also there is a feeling of mistrust between public and government in developing countries. Democracy should not be considered as a stable system of governance here like in the developed countries. Thus, people hesitate in sharing their ideas with the government leaders. In this regard, it is the joint responsibility of both government and business leaders to bridge this gap and make this transformation easier. Under these circumstances, a committed, honest and visionary leadership is required to meet the desired challenges for successfully setting up of six sigma philosophy. Government leaders and policy makers need to recognize, understand, and mark organizational challenges, especially the cultural factors, which creates hindrances to the sustainability of Six Sigma. Some reluctance can be observed on behalf of the government 
leaders and other related people in launching six sigma initiatives. The resistance in developing countries to accept Six Sigma is also related to the organizational challenges in launching this technique. Nevertheless, work has been done by some government agencies for the promotion of Six Sigma and some companies have seen tremendous success, while others have abandoned this approach or found it too difficult, because in Six Sigma, decisions are required to be based on data and statistics, not just on assumptions and anecdotal evidence. It starts from determining the need for a project, determining the cause of the problems being solved and then deciding what improvements it will make. In all these processes, data is required for decision making. This cumbersome work of data collection discourages the organizational heads to invest time and other resources in this newly developed concept of quality, which is used by Motorola and other large companies to successfully achieve positive changes in their organizations. The results of Six Sigma have the potential to benefit customers, employees, and shareholders. In order to effectively use the Six Sigma methodology, a substantial amount of time and resources must be allowed for a project.

\section{Organizational Challenges}

The organizational and structural challenges faced by developing countries in setting up six sigma encompasses but not limited to public perception, achieving operational and customer service excellence, waste reduction, and misconceptions regarding its implementation. For a sustainable and successful Six sigma programme, it is the basic need to resolve these doubtful queries against its implementation. The success of Six Sigma in the public sector of developing countries depends a lot on building a positive public perception of the projects, where contrary to developed countries whose customer base is well defined, a developing country customer base is much broader and includes people who may not directly benefit from the improvements identified by the methodology. It is the dilemma of most of the developing countries, that there is a lack of trust, commitment, sincerity and positive relations between the government and the public. Under these circumstances, public do not feel comfortable in paying taxes. Moreover, frequent shift over between dictatorships, monarchies and democracies has crumbled the infrastructure of most of the developing countries; poverty is also one of the root causes. In this scenario, it is really difficult to convince taxpayers about incorporating this new initiative in government projects because they are already dissatisfied with lavish government spending on their own perks and privileges. To initially address these concerns, governments need to effectively communicate the expected benefits and savings resulting from the improvement initiatives with the concerned stakeholders. For those governments, who plan to consider Six Sigma, picking the right project is critically important. Also, accountability and credibility of the project must be ensured at all cost. To start with, those projects can be selected initially, which appeal to a large segment of its taxpaying customer base. In the developing countries it is an estimated view that approximately $55 \%$ of small to medium sized organizations today have got no system of data collection and compilation. They carry their business transactions on the basis of centuries old non-conventional methods, while Six Sigma requires very thorough statistical data for its successful implementation. This is also true of most large public or private companies as well. 
Six Sigma can be regarded as a latest in the series of quality techniques that have been helping people to bring more quality in their lives. The Six Sigma methodology in particular has been widely used by organizations looking to streamline their processes and capitalize on opportunities. It undoubtedly has a potential to improve the business results of major organizations by ensuring that each step in the process contributes for the best possible outputs, which results in a sustainable progression from beginning to end. However, in developing countries, people are not so educated to understand multiple stages of different processes. Neither are they so customer conscious that they split each process into further divisions for its microscopic analysis.

Since the start of this technique in early 1980s the basic aim was to improve quality through statistical measurements and benchmarking. The concept entered the mainstream of public perception in the 1990s. Since then, Six Sigma has experienced wide range of success as well as failures. In the developed countries, it has become an important fixture among corporate cultures of the large multinational organizations (Darshak A. Desai \& Mulchand B. Patel., 2009). The Six Sigma process should not be regarded as a cumbersome undertaking. This methodology comprises five steps in which each step involves a series of actions to be completed before going to the next step. It includes Defining the customer, their critical issues and its core processes. Also, project boundaries and the process flow chart must be defined at the start. Measuring the performance of core business processes by collecting data to identify defects in those processes. These results are then compared with results from customer surveys to ensure their validity. Then analyze the data collected to find gaps between current performance and ideal performance. This step also includes the prioritization of processes and opportunities for improvement and reasons for observed variations. Improving the identified processes by developing creative solutions and lastly, Controlling the improvements by implementing the developed strategies with the help of an ongoing plan to monitor changes and prevent employees from going back to their old way of working.

\section{Difficulties in Implementation}

Implementing the Six Sigma methodology can become a very successful approach to process improvement. Many companies that have endeavored to implement Six Sigma have seen an improvement in their product quality, reduction in their costs and an increase in their efficiency level. However, sometimes times this success can also become a short term phenomenon if organizations fail to adequately consider all factors that can guarantee the long-term sustainability of those improvements.

Six Sigma implementation in developing countries still faces lot of difficulties. Incidentally there is really no plausible way to break Six Sigma process into pieces and then successfully implement just a segment of it because Six Sigma itself is an integrated process from beginning to end. So, it would be virtually impossible to break it down and cherry pick few aspects of this process to implement and then expect meaningful results. However, in developing countries, it is observed that the policies of government are short term and interim, rather most of them do not complete their tenure. This dis-continuity in the policies thus hampers the effectiveness of Six Sigma. On the other hand, efforts can be made to go for selective projects at the start. These selected projects should be easy to handle and must not be needing lot of resources for their completion according to Six Sigma methodology. 
Six Sigma focuses on the technical identification of different factors and then remedial measures are designed against them, interestingly; it often fails to cater for the human factor that result in the failure of nearly $60 \%$ of all Six Sigma initiatives that are taken by different organizations in developing countries. These failures indicate that companies should not focus on implementing Six Sigma in isolation. Rather, the need for human involvement in paramount in order to bring any significant change in the implementation of Six Sigma efforts. In developing countries, human factor gains more importance due to less automation and most of the time, public and private organizations depend on human capital more instead of machines due to cheap and easily available manpower. Many times, it is observed that those very aspects that make Six Sigma effective are also responsible for reducing its overall effectiveness. In this latest quality technique, cumbersome statistical analysis is required on the basis of data to identify defect areas, the correction of which can produce improved quality, decrease in costs and enhanced efficiency. Economic gains are generally set as an indicator of improvement for management that how much money a particular change can save for the company. Non-availability of high quality and precise data in most of the organizations of developing countries is a crucial factor that hampers its successful implementation.

It is observed that in developing countries factors such as; economic pressure, law and order situations and social pressures tend to bring long range variations in them. Thus, keeping in view the high costs required for Six Sigma projects, human behavior can also be incorporated into it. By doing so, management in the developing countries can try to achieve the same benefits without investing lot of resources in Six Sigma projects (Young Hoon Kwak \& Frank T. Anbari, 2006). The behavioral approach focuses on optimization of available human assets instead of making huge investments in procuring new hardware, software, and other equipment that also sometimes become necessary to implement many Six Sigma recommendations. One recent example noted that when a company applied this human capital approach to their projects, $70 \%$ of the shortlisted factors are found to be exactly the same as the findings of the Six Sigma team independently working on the same projects at the same company. This team was comprised of Six Sigma Green Belts, Yellow Belts, Black Belts and Master Black Belts.

It can also be researched that the combination of behavioral effect with six sigma technique produces better results or not. Some opinion is found to be against this effectiveness of incorporating both the Six Sigma and behavioral approaches simultaneously for better results. However, most of the people interviewed anticipate positive changes in the corporate culture by incorporating human factor in the process, and expected to gain significant benefits without putting large capital investments. Many people are also of the view that in the context of developing countries, where economic conditions are already worsened, it looks more appropriate that a reasonable effort can be made to bring a positive change in the behaviour of employees. It is not only economically viable but practically seems to be more sustainable. However, when an organization decides to make any significant change to its internal processes, especially to its people, just the initial talk of the intended change is tantamount to unsettle a workforce in its current routine. This situation can be further complicated if management fails to communicate its reasons for bringing this change and fails in demonstrating a strong follow up support for it. 


\section{Effectiveness of Six Sigma}

Nowadays, Six Sigma has become a buzzword in both the manufacturing and service industries of the world. The various methodologies used in Six Sigma are based on pure and precise data that help in reducing defects by restricting the number of possible defects to less than 3.4 defects per million. The methodologies are equally effective in both the manufacturing and service industries. In manufacturing industries, Six Sigma is mostly used for reducing the number of defects whereas in service industries, it is used mainly for increasing customer satisfaction.

Although many companies remained successful in reducing the number of defects through Six Sigma, its effectiveness is still under trial amid discussions in the business communities of the world. Some management experts are of the opinion that the analytical and statistical tools used in Six Sigma focuses on flaws at the completion of any process and do not look at the basic defects of the process. According to them, other quality management tools such as Total Quality Management (TQM) and Six Sigma are conceptually very close to each other and can be effectively used by Business organizations to improve their overall quality.

However, supporters of Six Sigma have a different viewpoint. They mostly prefer Six Sigma on the pretext that it is more than just a process improvement program and focuses on continuous quality improvements. They observe that Six Sigma concepts use the combination of statistical measurement tools with contemporary management techniques to achieve extraordinary results.

Strategic planning can be done in those areas that have far-reaching and tactical implications at the project selection stage. The basic purpose of strategic planning is to efficiently take those decisions and actions, which help in successful implementation of six sigma. Strategic planning can simply be considered as the combination of the leader's vision with the working of the organization. It may help in giving an entirely new direction to organizational growth. With the help of adequate planning, employees can overcome many hurdles in their efforts for the transformation of vision into tangible gains. However, in most of the public sector organizations in developing countries, status quo does not allow leaders to interact with their staff and subsequently transfer of vision from leaders to team members do not take place effectively. It results in rudderless thinking by the people in most of the public sector organizations. Another important concept is connecting with the customer. Customers should be involved with companies in defining their needs. The tools of Six Sigma makes this link easier between the key elements, activities, strategies and the vision, which leads to smooth sharing of ideas. The Six Sigma methodology allows effective communication of the vision to all stakeholders in a language understandable to them. Ironically, customers are not given so much importance here as in developed countries. People working in the government departments pay least attention to their visitors and those in private organizations also vary in their dealing with customers. However, change in the behaviour towards customer is witnessed in case of some leading private enterprises, who have taken a franchise from top brands of the world.

Change agents in the developing countries must be mindful of one key ingredient in their change efforts that changes in behaviour of people precede changes in processes or procedures and not vice versa. People understandably offer resistance to change because they are presently operating within a comfort zone. They must be convinced initially that why there is something wrong with the way they perform, especially if they are working within parameters set forth for them earlier by the organization itself. 
There is a common perception in the developing countries that people who are asked to implement a change first need to clarify why a specific change is required and whether their change efforts can make any difference within their areas of influence or not. If people are properly taken into confidence regarding these efforts, employees are generally more responsive and adaptive in implementing this change for a longer term. It not only results in a sustainable change but also helps in generating a feeling of involvement and ownership of the desired eventful changes.

Behavioral change that requires less capital expenditure as compared to other infra structural changes gives an ample opportunity to management to show more empathy towards their employees. In return, management can surely enjoy many of the same financial and operating benefits as other heavy investment can bring for the organization. While doing so, it seems that the overall yield of developing countries can increase and it would cast a positive effect in overall efficiency. Moreover, by utilizing the behavioral approach to implement change in the corporate culture, management can indeed enjoy many of the same benefits that Six Sigma and other quality initiatives bring for the organizations. These changes also have a better chance of long term sustainability.

\section{Some common misunderstandings}

This new quality concept is interestingly not taken in its true perspective by the people of developing countries, where literacy rate is still hovering around 30 percent. Some of the misconceptions can be interpreted as:

- Applicable in manufacturing sector

- Duplication of functions

- Extra effort

- Needs enormous training

- $\quad$ Requires multi disciplined teams

- Very statistical

- Needless investment

\section{Applicable in manufacturing sector}

Most of the initial work of Six Sigma is carried out in manufacturing industries. It leads people to believe that it is only limited and designed for manufacturing process. On the contrary, it has the potential to improve all process that is related to customers, products and services.

\section{Duplication of functions}

Another objective of Six Sigma is to curtail every bit of organizational waste and then reinvesting them back into the system channel. With the poor economic conditions in developing countries, there is no room to waste money through the duplication of functions. Six Sigma is about nurturing any function that adds significant value to the customer and adding additional revenue for the organization. 


\section{Extra effort}

Believers of this concept feel that in the presence of other quality tools, it is not required to go for this newly developed technique. They consider it an extra burden on the budget of organization. However, in reality, most of the organizations, who have successfully implemented Six Sigma have gained huge profits by improving their processes.

\section{Needs enormous training}

It is general mis-perception that lot of training is required for achieving the required goal.

\section{Requires multi disciplined teams}

It is believed that Six Sigma teams need to be too large, which results in the amalgamation of different ideas and thoughts, hence no one can get the idea what the other person is doing.

\section{Very statistical}

It is a common understanding that the advanced statistical tools, which are extremely valuable in identifying and solving problems, need people to possess an analytical background and understanding in the wise use of these tools. However, they make a common mistake by forgetting that understanding of all the mathematics behind these statistical techniques is not required. The wise application of statistical techniques can be achieved with the help of new and easy to use statistical softwares.

\section{Needless investment}

This assumption is again proved wrong because those organizations, who have wisely implemented Six Sigma, have obtained a very high rate of return on their investment.

\section{Six sigma and other quality programs}

In today's highly competitive environment, there is mounting pressure on organizations to enhance their quality and customer satisfaction while decreasing costs and wastages. This becomes an increasingly difficult challenge for developing countries, where there is a scarcity of resources. Thus, it is imperative for any industry or organization to identify the shortcomings and overcoming them to meet the world challenges (Sean P. Goffnett., 2004). If Six sigma is implemented wisely, it can surely help organizations to learn and excel at the challenges they encounter. Regarding Six Sigma there is a false assumption in its ideology with other company initiatives. Six Sigma cannot and should not be treated as a separate identity apart from other quality initiatives of the company, rather, it must be seen in close association with other programs and initiatives at a higher level as part of an overall business strategy. Six Sigma is not supposed to replace other initiatives, but it simultaneously offers a tactical methodology to find out the best approach for a given situation. 
The major components to consider during Six Sigma implementation are its metrics and strategy to be followed. Some people are of the opinion that Six Sigma is merely a thorough application of basic and advanced statistical tools throughout an organization. Some feel that Six Sigma consultants and training organizations have simply repackaged the old statistical components of their previous Total Quality Management (TQM) programs and renamed them. Others view Six Sigma as merely a newer version of Total Quality Management (TQM). They see it as an advanced form of TQM in which various improvement systems are integrated with the help of statistical analysis for better performance (Ywende Adeyemi, 2004). However, the ultimate goal of Six Sigma, unlike from other quality tools is not only improvement for the sake of improvement, but rather the creation of economic wealth for both customer and organization in accordance with their own perspectives. In this context, Six sigma can be better regarded as a major business initiative rather than merely a quality program. This implies that Six Sigma is not a replacement of existing and ongoing quality initiatives, but can be regarded as an additional support to further strengthen the ongoing efforts to improve the economic growth of an organization.

\section{Six Sigma and the Public Sector of developing countries}

Six Sigma methodologies can be applied in public sector organizations of developing countries at both at macro and micro levels. At macro level it can be very helpful as a catalyst for achieving economic viability. In this regard, Six Sigma methods can be used to develop a measurable, data-based and closed loop national policy. Getting a cue from developed countries, this technique can also be applied by the public sector organizations to make long term policies for its permanent incorporation. By doing this, Six Sigma can become a solid feature o all government run projects. At micro level the application of Six Sigma focuses to improve the way government is running its day to day activities. The objective of this effort is to make the under utilizing public agencies of developing countries more effective, efficient and economically viable to support national policies. It not only restores public confidence in government policies but also bring an improvement in the national economic conditions of developing countries.

On the basis of interviews with different leaders as well as middle managers of public sector organizations, it is observed that the main difficulty of implementing this procedure at the public level depends on the prevailing culture and the attitude. Unfortunately, lack of positive attitude in taking ownership of the problem is common in most of the oldfashioned and hierarchical public agencies of developing countries. Thus, in the absence of anyone taking the lead to improve departmental working, these kinds of initiatives have the tendency to die down during their infancy. So the successful implementation of Six Sigma instantly requires an adjustment to the organizational culture and a change in the mindset of its staff. In this endeavor, several strategies need to be carried out to overcome resistance against the change efforts in public agencies due to technical, political, individual and organizational factors. 


\section{Relevant training}

Relevant training can be found as another crucial factor in the successful implementation and deployment of Six Sigma initiatives in case of developing countries. It is appropriate to communicate all relevant details of Six Sigma before the start of project and then arrange training classes for the improvement of basic skills among the people, who are intended to work on these projects. The management also needs to ensure that the training contents and sessions be structured in such a way that it must be relevant to employees' everyday jobs. Because, it is observed that in today's cut throat competitive job markets, any initiative, no matter how brilliant and effective it may be, as long as it is not aligned with an individual's job performance, it usually gets a very lukewarm response. The staff can develop good understanding of Six Sigma methodology, statistical tools analytical techniques through a series of training sessions and workshops under the supervision of qualified trainers. During these training activities, it can be made compulsory for consultants and trainers to integrate these new initiatives of Six Sigma with the ongoing processes in the organizations. The high impact and convenient projects can be selected in the pilot implementation stage to avoid disappointment and frustration among people in organizations.

\section{Performance based remuneration}

In order to encourage Six sigma initiatives in the developing countries, there is a need of associating some financial benefits for those people, who come forward and take a lead in its promotion. It can be done by giving some incentives on the successful implementation of six sigma projects. In the developed countries it is estimated that more than $60 \%$ of the top performing companies practicing Six Sigma link their annual bonuses and increments to their business strategies and Six Sigma projects.

\section{Mistakes and Remedies}

Ironically, corruption, colonialism and nepotism have so much deep rooted in the day to day matters of developing countries that introduction of Six Sigma has become a great challenge for the quality seekers in this part of the world. Under these circumstances, promotion of Six Sigma culture requires an honest, trusted, committed and accountable leadership.

Government agencies are generally enjoying the monopoly of providing services without real competition from other competitors. Under this controlled market conditions in which no other party is allowed to operate, management of these organizations are least pushed about any customer expectations and quality improvement initiatives. It is evident in many organizations that the projects of Six Sigma are conceived by the few quality conscious managers but during the implementation stages, concerned process owners find no true urgency for project initiation and completion. It is thus advisable not to start and invest in these projects unless all the stakeholders are on board to make it a real success.

On the contrary many private companies who have tried to develop and implement Six Sigma consider it a brilliant technique in solving chronic, complicated and cross-functional problems. Among these organizations, some remained unsuccessful to benefit completely 
from the advantages of Six Sigma. On careful analysis, this failure is found to be due to untimely plucking of all low hanging fruits.

Slowing down of Six Sigma after few years is not an unusual phenomenon observed in the developing countries. Once the key opportunities are identified and acted upon, many companies are either found to ease down and again start following their natural course, with returns diminishing at a steady pace over time or once organizations successfully achieved the Six Sigma goal, they consider it good enough and stop the process of continuous improvement. This mindset of contentment allows quality to deteriorate. Organizations looking for a Six Sigma deployment must not be solely dependent on one executive's drive. It is thus required to create a system where the process owner asks for the creation of Six Sigma projects to improve their performance by aligning it with their business needs. Under these conditions, it is imperative for the public and the leading private organizations of developing countries to come forward and join hands with each other in their efforts to promote this latest quality concept.

Six Sigma needs constant feedback regarding monitoring and evaluation of projects under progress. Hence effective Six Sigma implementation may also be requiring a reasonable communication infrastructure to receive, organize and transfer inputs and feedbacks into effective decision making for the organization. In this regard, all the affected people be involved, otherwise a change may be wrongly implemented that can make the job of someone further difficult. Under these circumstances, cross functional teams can effectively play their role to solve inter departmental problems to its optimum level. However, most of the private sector organizations in these countries either do not pay proper attention to improve the capabilities of their staff or simply cannot afford it. Similarly, most of the public sector organizations depend on some donations and training packages from developed countries to send their people abroad for getting these trainings.

Human capital is one of the most important assets of any company. Proper planning is required to enhance the core competencies of these people. Without a trained staff, all the initiatives are having bleak chances of success because in the absence of a strong technological infrastructure in most organizations of the developing countries, a lot depends on human beings to deliver. Thus, the aim in this scenario should be to achieve the improved and sustainable success for organizations by providing all necessary and latest techniques that are required for it. Another factor observed in ineffective Six Sigma planning is poor communication. One should not expect the vision to be shared effectively if it is poorly communicated. It is therefore mandatory to make the statement as clear and simple as possible - and to the point. Six Sigma projects mainly revolve around the strategic planning of an organization. It means that the company leadership must take into account this unique combination of strategies and action plans that allows robustness with flexibility to deal with unique challenges of today's competitive market (Lora L. Loethen, 2008). In this regard, it must be taken care that the plans and objectives should be as clear to people as it is to leaders of the different public and private sector organizations.

Since, Six Sigma gained prominence as an efficient and effective quality management technique; many large organizations have used it to improve the quality of their products and services. However, researchers feel that the full potential of Six Sigma is yet to discover in developing countries. Although most of the small and medium enterprises in these countries have all the resources to implement such programs, yet they feel that it is meant only for large organizations. These companies often do not realize that Six Sigma offers the 
same benefits to both large as well as small business enterprises. Their only difference can be the magnitude of profits, which itself is proportional to the size and kind of an organization implementing Six Sigma initiatives.

\section{The Future of Six Sigma in developing countries}

Although Six Sigma appears quite similar to other quality management tools such as TQM or Kaizen Events, but in reality, it is quite different. Other quality management programs soon reach a stage after which no further quality enhancements can be achieved. Six Sigma, on the other hand operates differently, as it focuses on the improvement of processes and not the end results, in which processes are gradually improved from one level to another. This means that Six Sigma has the potential to surpass other quality management programs in the future. However, fast changing governments and sometimes even shifting from dictator ships to democracies and vice versa pose a serious threat to its sustainable growth, because under these circumstances, everyone in the power corridors prefer short term schemes for their quick results and thus may not be so much enthusiastic in applying projects on the basis of this single packaged technique. In this situation, it is imperative for the developed countries to train people in both the government and the private sector of its importance and fruitfulness. Only then, benefits of Six Sigma can be expected to trickle down slowly in comparatively less developed towns and then ultimately to rural segments of the society.

The scope of Six Sigma is also much wider than other quality management programs and thus, its application can be expanded to most of the business organizations in developing countries. Very encouraging growth in the awareness of Six Sigma among small and medium enterprises is also witnessed. At the initial stages of this concept, its growth is mostly confined to the urban areas of the developing countries. However, large numbers of people are living in rural areas, where businesses are not so well documented, therefore, its expansion may face some problems but awareness campaigns by the government agencies to realize people of its benefits can be very useful for its promotion.

Although, the challenges in implementing the six sigma method are immense, yet growing awareness in the people of developing countries is also very encouraging. Many organizations have now started incorporating the trainings of Six Sigma in their future organizational development plans. It is expected that when these people start delivering in their respective positions, results of this business management technique will become more obvious to the organizational leaders. Many technical and educated people in these countries have now realized that Six Sigma is a highly disciplined approach that helps an organization focusing on the critical processes for sustainable improvement. In this regard, lot of help is required from data, so, organizations have also started paying proper attention on the documentation and reliability of data for further analysis by Six Sigma teams.

Six Sigma can also be effectively integrated into the management system of the governments with proper planning, leadership commitment and most importantly the political will to make changes. In developing countries, most of the national leaders usually initiate any new improvement drives and policies after being triggered by certain general conditions such as budget cut; economic crisis; electorates or succumbing to taxpayers pressure for better governance; but the complexities and magnitudes of problems being faced by these countries are gigantic and it is simply out of question that governments alone will be able to 
handle them efficiently. In this situation, private entrepreneurs should come forward and must join hands with their respective governments in improving the fast deteriorating situation of big public sector organizations. Six Sigma can rightly be called a superb strategy that has the potential to deliver equally well in both private and public sector and give the developing countries a positive way to come in a race with developed countries.

\section{References}

Darshak A. Desai, Mulchand B. Patel. (2009). Impact of Six Sigma in a developing economy: Analysis on benefits drawn by Indian industries, Journal of Industrial Engineering and Management, pp 517-538, ISSN: 2013-0953

Lora L. Loethen. (2008). Six Sigma Leadership, pp 1-25, ISBN-10:1-59942-690-0

Sean P. Goffnett. (2004). Understanding Six Sigma: Implication for industry and education. Journal of Industrial Technology, Vol. No. 20

Young Hoon Kwak, Frank T. Anbari. (2006). Benefits, obstacles and Future of Six Sigma Approach, Technovation, pp 708-715

Ywende Adeyemi. (2004). Analysis of Six Sigma at Small Vs. Large Manufacturing Companies, pp 1-88, University of Pittsburg.

http:/ / www.sixsigmaiq.com/searchresults.cfm?Searchterms=Mark\%20Aesch

http://www.ftpress.com/title/013143988X

http://www.articlesbase.com/management-articles/future-of-six-sigma-differentviewpoints-57635.html

http://www.computer.org/portal/web/csdl/doi/10.1109/CSO.2009.419

http://hdl.handle.net/2320/5619 


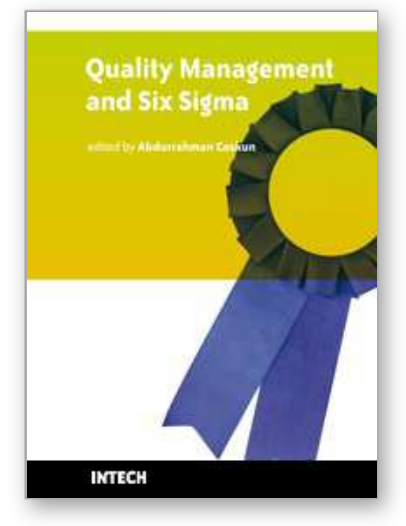

\author{
Quality Management and Six Sigma \\ Edited by Abdurrahman Coskun
}

ISBN 978-953-307-130-5

Hard cover, 276 pages

Publisher Sciyo

Published online 16, August, 2010

Published in print edition August, 2010

If you do not measure, you do not know, and if you do not know, you cannot manage. Modern Quality Management and Six Sigma shows us how to measure and, consequently, how to manage the companies in business and industries. Six Sigma provides principles and tools that can be applied to any process as a means used to measure defects and/or error rates. In the new millennium thousands of people work in various companies that use Modern Quality Management and Six Sigma to reduce the cost of products and eliminate the defects. This book provides the necessary guidance for selecting, performing and evaluating various procedures of Quality Management and particularly Six Sigma. In the book you will see how to use data, i.e. plot, interpret and validate it for Six Sigma projects in business, industry and even in medical laboratories.

\title{
How to reference
}

In order to correctly reference this scholarly work, feel free to copy and paste the following:

Ali Rizwan Ali (2010). Six Sigma And Developing Countries, Quality Management and Six Sigma, Abdurrahman Coskun (Ed.), ISBN: 978-953-307-130-5, InTech, Available from: http://www.intechopen.com/books/qualitymanagement-and-six-sigma/six-sigma-and-developing-countries

\section{INTECH}

open science | open minds

\section{InTech Europe}

University Campus STeP Ri

Slavka Krautzeka 83/A

51000 Rijeka, Croatia

Phone: +385 (51) 770447

Fax: +385 (51) 686166

www.intechopen.com

\section{InTech China}

Unit 405, Office Block, Hotel Equatorial Shanghai

No.65, Yan An Road (West), Shanghai, 200040, China

中国上海市延安西路65号上海国际贵都大饭店办公楼 405 单元

Phone: +86-21-62489820

Fax: $+86-21-62489821$ 
(C) 2010 The Author(s). Licensee IntechOpen. This chapter is distributed under the terms of the Creative Commons Attribution-NonCommercialShareAlike-3.0 License, which permits use, distribution and reproduction for non-commercial purposes, provided the original is properly cited and derivative works building on this content are distributed under the same license. 